\title{
Inflammatory Myofibroblastic Tumor of the Urinary Bladder-A Case Report with Review of Literature
}

\author{
Mahesh Deshmukh1*, Radhika Pagey', Komal S. Galani1, Prasanna Joshi², Amol Bitey³, \\ Mrunmayi Kotwal ${ }^{1}$ \\ ${ }^{1}$ Department of Pathology, Rashtra Sant Tukadoji Regional Cancer Center, Nagpur, India \\ ${ }^{2}$ Department of Surgery, Rashtra Sant Tukadoji Regional Cancer Center, Nagpur, India \\ ${ }^{3}$ Department of Radiology, Rashtra Sant Tukadoji Regional Cancer Center, Nagpur, India \\ Email: [drmkdeshmukh@gmail.com
}

Received 7 August 2014; revised 28 August 2014; accepted 18 September 2014

Copyright (C) 2014 by authors and Scientific Research Publishing Inc.

This work is licensed under the Creative Commons Attribution International License (CC BY). http://creativecommons.org/licenses/by/4.0/

(c) (i) Open Access

\begin{abstract}
Inflammatory myofibroblastic tumor (IMT) is a rare neoplasm with unknown malignant potential that has been described in most organ systems. We herein present a case of a young female who presented with macroscopic hematuria. An IMT of the urinary bladder which was not suspected after clinical, radiological and surgical work-up was diagnosed microscopically and confirmed by immunohistochemistry. A close clinical follow-up is recommended because of the unknown biological behavior of this tumor. A brief review of literature is also presented here.
\end{abstract}

\section{Keywords}

Inflammatory Myofibroblastic Tumor, Spindle Myoepithelial Cell Proliferation, Urinary Bladder

\section{Introduction}

Inflammatory myofibroblastic tumor (IMT) is a rare neoplasm composed of spindle cells with an associated inflammatory cell infiltrate. It has been described in most organ systems; however IMT of the urinary bladder is a very uncommon spindle cell tumor, which has an undetermined malignant potential. It is often mistaken for sarcoma of the bladder and because the former can be managed with a bladder-preserving approach, i.e., transurethral resection (TUR) or partial cystectomy, distinguishing it from the latter is of critical importance [1] [2].

We report a case of IMT arising from urinary bladder in a young adult female and discuss its clinico-radi-

\footnotetext{
${ }^{*}$ Corresponding author.
}

How to cite this paper: Deshmukh, M., Pagey, R., Galani, K.S., Joshi, P., Bitey, A. and Kotwal, M. (2014) Inflammatory Myofibroblastic Tumor of the Urinary Bladder-A Case Report with Review of Literature. Open Journal of Pathology, 4, $176-180$. http://dx.doi.org/10.4236/ojpathology.2014.44023 
ologic presentation, histopathologic and immunohistochemical diagnostic criteria, differential diagnosis, behavior, and management.

\section{Case History}

A 26-year-old female presented with a history of painless gross hematuria since 15 days. She had no other symptoms, no previous medical history and had never undergone bladder instrumentation or procedures. Physical examination was unremarkable. Urine routine examination revealed reddish turbid urine with presence of albumin (30 mg/dl). Microscopic examination showed plenty of RBCs, few pus cells and epithelial cells. Urine cytology did not suggest any malignancy. All blood investigations including renal function test, coagulation profile and hemogram were within normal range.

Multidetector CT scan with contrast, of whole abdomen, was performed which revealed a hypodense, rounded, polypoidal mass at postero-right lateral wall of urinary bladder, measuring $4.5 \times 4.0 \times 3.8 \mathrm{~cm}$ (Figure 1). The margins were regular and showed intense post contrast enhancement. Few small enlarged lymph nodes at internal iliac region were seen, the largest measuring $1.5 \mathrm{~cm}$ in diameter. Liver, spleen, pancreas, gall bladder \& bilateral kidneys were unremarkable. The chest radiograph showed nodular infiltrates in bilateral upper lobes probably of infective origin.

The patient underwent cystoscopy which showed large sessile smooth-walled growth arising from the right lateral wall of the urinary bladder while the remaining mucosa was unremarkable. TUR of bladder growth was performed. Histological examination revealed a spindle cell tumor with cells arranged in long and short fascicles, at places showing a whorled growth pattern, accompanied by mononuclear cell infiltration consisting of plasma cells \& lymphocytes infiltrating the muscularis layer on a myxoid stroma (Figure 2). Foci of collagen deposition were also seen. The overlying lining epithelium was attenuated. There was no evidence of any significant nuclear atypia, mitotic activity or necrosis. On immunohistochemical evaluation, the tumor cells expressed pancytokeratin (AE1-AE3) with focal positivity for smooth muscle actin (SMA) and weak positivity for Anaplastic Lymphoma Kinase-1 (ALK-1) (Figure 3). Tumor cells were negative for desmin. CD 138 (Figure 3) highlighted the interspersed plasma cells. A diagnosis of IMT was made. A completion TUR was done while preserving the bladder and the patient was kept on close follow-up. After 1 year of follow up, the patient is clinically asymptomatic and her USG pelvis did not show any growth in the bladder.

\section{Discussion}

IMT is a rare spindle cell neoplasm of the urinary bladder, characterized by atypical spindle cell proliferation accompanied by inflammatory cell infiltrate comprising primarily lymphocytes and plasma cells. The first case was reported by Roth in 1980 [3]. It is also known as pseudosarcoma, atypical fibromyxoid tumor, atypical

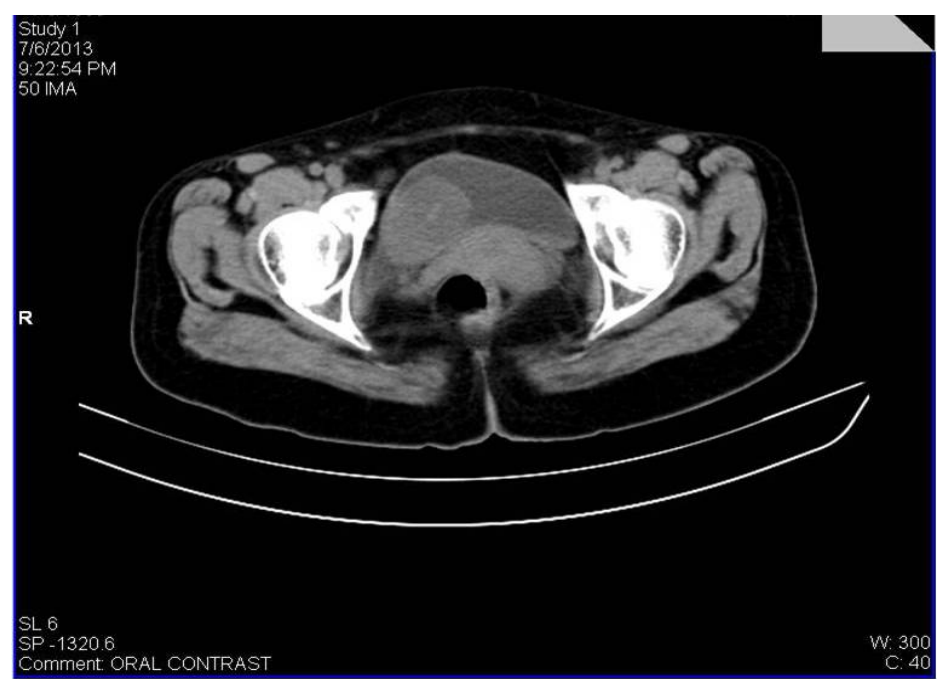

Figure 1. Abdominal CT scan showing a polypoidal growth in the bladder measuring $4.5 \mathrm{~cm}$. 


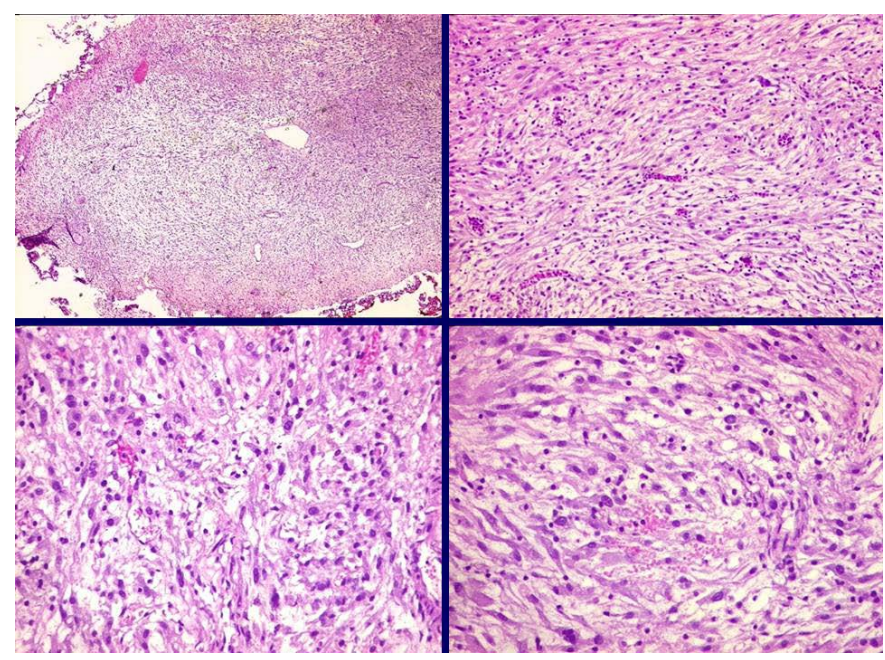

Figure 2. Section showing attentuated urothelial lining epithelium with underlying spindle cell tumor composed of oval-to spindle shaped cells admixed with lymphocytes and plasma cells on a myxoid stroma (H \& E; top left-scanner view, rest-200×).

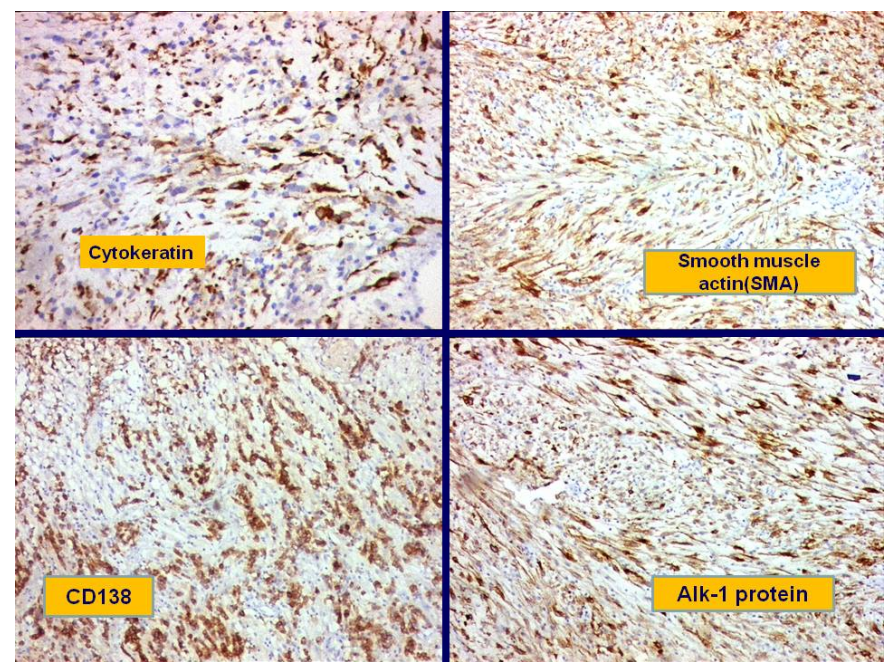

Figure 3. Immunohistochemical profile of IMT: Tumor cells express cytokeratin, SMA and Alk-1 protein while CD 138 highlights interspersed plasma cells (200×).

myofibroblastic and plasma cell granuloma [4]. IMT may arise at any anatomical site, including lung, soft tissues, retroperitoneum, and bladder. It may affect any age group, but it is more common in children and young adults with slight female preponderance (M:F ratio 3:4).

The origin of IMT is controversial, but a recent report suggests that it is neoplastic because of aggressive behavior, involvement of chromosome 2p23, and congenital clonality. Due to the marked inflammatory pattern, infectious and autoimmune etiologies have been suspected for the pathogenesis of IMT. Some microbiological agents and autoimmune diseases were blamed, but are not the yet clearly identified etiology of IMT. For now, the etiology of IMTs remains unclear [1].

Patients with IMT of the urinary tract usually present with painless macroscopic hematuria, but may also have lower urinary tract symptoms or a suprapubic mass [1]. Reported tumor size ranges from $1-37.5 \mathrm{~cm}$ in diameter, although the typical bladder lesion is less than $2 \mathrm{~cm}$, and is grossly described as having a circumscribed; solitary or multinodular; firm, gray white, or yellow; with fascicular or myxoid appearance. The index case had a $4.5 \mathrm{~cm}$ solitary bladder tumor. Endoscopically and radiologically indistinguishable from malignant tumors, the histo- 
logic appearance varies but usually includes an element of myofibroblast and fibroblast spindle cells, a collagenous or myxoid matrix, and inflammatory cells consisting of plasma cells, lymphocytes, and eosinophils, which may mimic both sarcomas and spindle-cell carcinomas. The reported mitotic index ranges from 0 to 20 mitoses/10 high-power fields with most IMTs having a mitotic count of less than 5 . Necrosis is usually quite rare to absent [5].

In young adult patients, the spectrum of urinary bladder neoplasms is distinctly different from that of older adults and elderly patients. In general, bladder neoplasms are uncommon in young adult patients [3]. The differential diagnosis of IMT in the urinary bladder must include benign lesions, such as postoperative spindle cell nodule, leiomyoma or solitary fibrous tumors, and malignant lesions, in particular rhabdomyosarcoma in children and leiomyosarcoma in adults, and sarcomatoid carcinoma.

Postoperative spindle cell nodule is a similar proliferative bladder lesion composed of mixed inflammatory and myofibroblastic-type components; its chief distinction from IMT lies in the fact that it occurs in a setting of prior instrumentation or surgical procedure. Harik et al. have proposed that in adults, IMT and postoperative spindle cell nodule may be combined into a single diagnostic category, designated "pseudosarcomatous myofibroblastic proliferation (PMP)" [4]. IMT is distinguished from sarcomas and sarcomatoid carcinomas by lack of both marked cytologic atypia and atypical mitotic figures. Positive ALK-1 favors IMT [1]. Positivity for ALK-1 by immunohistochemistry ranges from $33 \%$ to $89 \%$, whereas ALK-1 protein expression in leiomyosarcoma and sarcomatoid urothelial carcinoma has not been reported, suggesting that ALK-1 immunohistochemical studies may be useful in the differentiation of IMT from other spindle cell lesions in the urinary bladder [6]. The ALK-1 reactivity correlates with local recurrence [2] and muscle invasion [7] [8]. Although a number of cases of rhabdomyosarcoma may show expression of ALK-1, particularly those of alveolar subtype, these lesions usually also express desmin and myogenin or myoD1, and show characteristic morphologic features that allow identification and distinction from IMT. However, both epithelial and myogenic markers can be expressed in IMT and may lead to a misdiagnosis of leiomyosarcoma, and rhabdomyosarcoma [9] [10].

Development of optimum treatment strategies and evaluation of treatment results are complicated by the paucity of cases and by the fact that not all authors describe pediatric IMT and adult PMP separately. Treatment largely relies upon surgical excision, coupled in some cases with chemotherapy, steroids, or radiation therapy [1]. Due to the mixed inflammatory and myofibroblastic nature of these tumors there has been increasing interest in using anti-inflammatory treatment in order to reduce tumor size before surgical excision [1]. The biologic behavior of bladder IMT is variable and unpredictable. Some lesions recur after surgery; infrequently, metastases develop. Consequently, these lesions are regarded as neoplasms with intermediate biologic behavior [11] [12].

Although more than 30 years have passed since its first description, several questions remain unanswered regarding low grade myofibroblastic proliferations of the urinary bladder. The most urgent problem seems to be both the nomenclature and the real nature of these lesions. In addition, in most cases, the histopathologic appearance alone does not help us forecast the clinical behavior of this myofibroblastic proliferation.

\section{Conclusion}

We conclude that IMT of urinary bladder is a very rare but distinctive neoplasm with intermediate malignant potential. High index of suspicion is required for diagnosis. Definite diagnostic criteria of IMT are spindle cell proliferation, presence of stellate cells, lymphoplasmacytic infiltrates, and scattered mitoses in myxoid stroma. Immunohistochemistry is very important to confirm the diagnosis. IMT may demonstrate positivity for Anaplastic lymphoma kinase, Vimentin, SMA, and Cytokeratin. IMT exhibits morphologic and immunophenotypic overlap with malignant spindle cell tumors of the urinary bladder and diagnostic distinction from these tumors can be problematic. Surgical resection is the treatment of choice.

\section{Conflict of Interest}

None.

\section{Source of Support}

None. 


\section{Consent}

Written informed consent was obtained directly from the patient for publication of this case report and any accompanying images.

\section{Acknowledgements}

We would like to acknowledge the help of Dr. Santosh Menon, Dr. Prafulla Chahande, Dr. Suhas Salpekar and the technical staff incharge Mr. Sable and Mrs. Rekha for their kind help and co-operation.

\section{References}

[1] Lecuona, A.T., Van Wyk, A.C., Smit, S.G., Zarrabi, A.D. and Heyns, C.F. (2012) Inflammatory Myofibroblastic Tumor of the Bladder in a 3-Year-Old Boy. Urology, 79, 215-218. http://dx.doi.org/10.1016/j.urology.2011.04.052

[2] Rao, R.N., Ranjan, P., Singla, N. and Pandey, R. (2012) Inflammatory Myofibroblastic Tumor of the Urinary Bladder Diagnosed by Anaplastic Lymphoma Kinase Immunostaining. Urology Annals, 2, 115-118.

http://dx.doi.org/10.4103/0974-7796.95567

[3] Williamson, S.R., Lopez-Beltran, A., MacLennan, G.T., Montironi, R. and Cheng, L. (2013) Unique Clinicopathologic and Molecular Characteristics of Urinary Bladder Tumors in Children and Young Adults. Urologic Oncology: Seminars and Original Investigations, 31, 414-426. http://dx.doi.org/10.1016/j.urolonc.2010.08.003

[4] Harik, L.R., Merino, C., Coindre, J.M., Amin, M.B., Pedeutour, F. and Weiss, S.W. (2006) Pseudosarcomatous Myofibroblastic Proliferations of the Bladder: A Clinicopathologic Study of 42 Cases. The American Journal of Surgical Pathology, 30, 787-794. http://dx.doi.org/10.1097/01.pas.0000208903.46354.6f

[5] Alquati, S., Gira, F.A., Bartoli, V., Contini, S. and Corradi, D. (2013) Low-Grade Myofibroblastic Proliferations of the Urinary Bladder. Archives of Pathology \& Laboratory Medicine, 137, 1117-1128.

http://dx.doi.org/10.5858/arpa.2012-0326-RA

[6] Sukov, W.R., Cheville, J.C., Carlson, A.W., Shearer, B.M., Piatigorsky, E.J., Grogg, K.L., et al. (2007) Utility of ALK-1 Protein Expression and ALK Rearrangements in Distinguishing Inflammatory Myofibroblastic Tumor from Malignant Spindle Cell Lesions of the Urinary Bladder. Modern Pathology, 20, 592-603. http://dx.doi.org/10.1038/modpathol.3800776

[7] Montgomery, E.A., Shuster, D.D., Burkart, A.L., Esteban, J.M., Sgrignoli, A., Elwood, L., et al. (2006) Inflammatory Myofibroblastic Tumors of the Urinary Tract: A Clinicopathologic Study of 46 Cases, Including a Malignant Example of Inflammatory Fibrosarcoma and a Subset Associated with High-Grade Urothelial Carcinoma. The American Journal of Surgical Pathology, 30, 1502-1512. http://dx.doi.org/10.1097/01.pas.0000213280.35413.1b

[8] Freeman, A., Geddes, N., Munson, P., Joseph, J., Ramani, P., Sandison, A., et al. () Anaplastic Lymphoma Kinase (ALK 1) Staining and Molecular Analysis in Inflammatory Myofibroblastic Tumours of the Bladder: A Preliminary Clinicopathological Study of Nine Cases and Review of the Literature. Modern Pathology, 17, 765-771. http://dx.doi.org/10.1038/modpathol.3800078

[9] Tsuzuki, T., Magi-Galluzzi, C. and Epstein, J.I. (2004) ALK-1 Expression in Inflammatory Myofibroblastic Tumor of the Urinary Bladder. The American Journal of Surgical Pathology, 28, 1609-1614. http://dx.doi.org/10.1097/00000478-200412000-00009

[10] Iczkowski, K.A., Shanks, J.H., Gadaleanu, V., Cheng, L., Jones, E.C., Neumann, R., et al. (2001) Inflammatory Pseudotumor and Sarcoma of Urinary Bladder: Differential Diagnosis and Outcome in Thirty Eight Spindle Cell Neoplasms. Modern Pathology, 14, 1043-1051. http://dx.doi.org/10.1038/modpathol.3880434

[11] Coffin, C.M. and Fletcher, J.A. (2002) Inflammatory Myofibroblastic Tumour. In: Fletcher, C.D., Unni, K.K. and Mertens, F, Eds., World Health Organization Classification of Tumours: Tumours of Soft Tissue and Bone, IARC Press, Lyons, 91-93.

[12] Yagnik, V., Chadha, A., Chaudhari, S. and Patel, K. (2010) Inflammatory Myofibroblastic Tumor of the Urinary Bladder. Urology Annals, 2, 78-79. http://dx.doi.org/10.4103/0974-7796.65106 
Scientific Research Publishing (SCIRP) is one of the largest Open Access journal publishers. It is currently publishing more than 200 open access, online, peer-reviewed journals covering a wide range of academic disciplines. SCIRP serves the worldwide academic communities and contributes to the progress and application of science with its publication.

Other selected journals from SCIRP are listed as below. Submit your manuscript to us via either submit@scirp.org or Online Submission Portal.
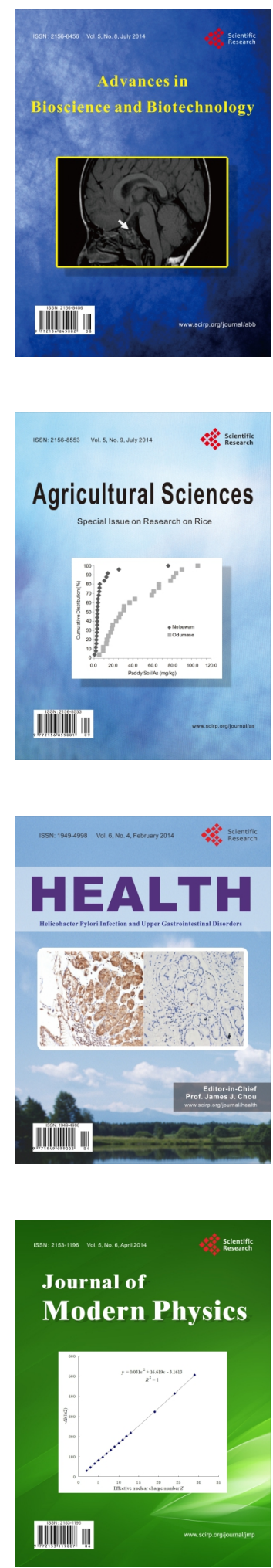
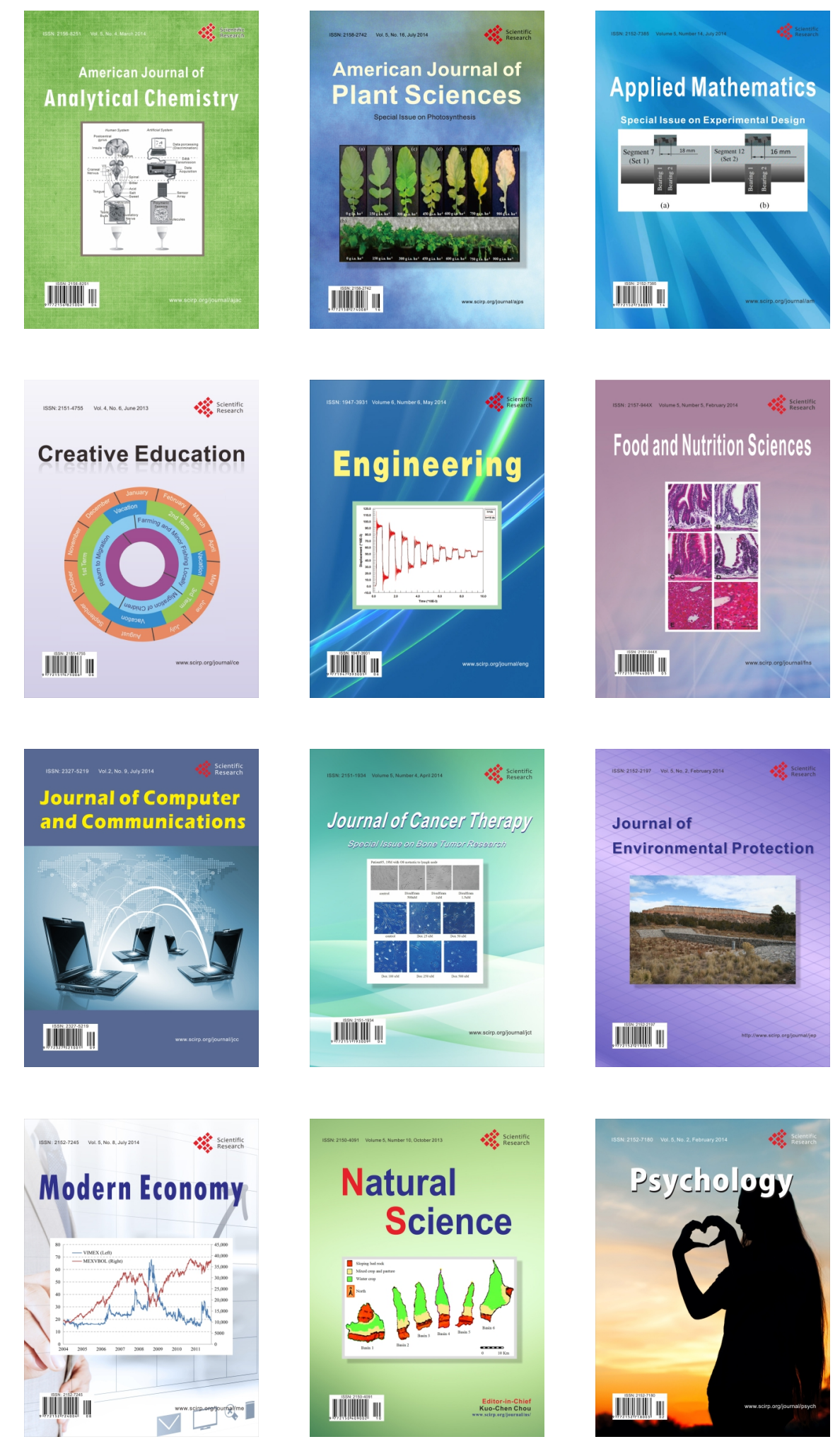